\title{
Correction to: Perceptions, Beliefs, and Experiences of Asians and Micronesian Islanders on Family Health History Genetic Cancer Screening Community Outreach
}

\author{
Connie Kim Yen Nguyen-Truong ${ }^{1}$ (1) $\cdot$ Andra Davis $^{2}$ (D) Vananh Minh Nguyen Vuong ${ }^{3} \cdot$ Kim Quy Vo Nguyen $^{3}$. \\ Anthony My Truong ${ }^{4} \cdot$ Jacqueline Leung ${ }^{5,6}$
}

Published online: 2 October 2021

(c) American Association for Cancer Education 2021

\section{Correction to: Journal of Cancer Education https://doi.org/10.1007/s13187-021-02085-0}

The original version of this article has a missing acknowledgment.

\section{Acknowledgments}

The authors are appreciative of the Centers for Disease Control and Prevention [\# 1NU58DP006701-01-00] that funded in part the study. The authors thank the ScreenWise Program Access Coordinator Paulina Almaraz, MPH, and the ScreenWise Program Genetics Coordinator Summer Lee Cox, MPH, at the Oregon Health Authority Public Health Division for their review of the study design. The authors thank Dr. Kandy S. Robertson, PhD, Scholarly Professor,
Program Leader in English, and Writing Center Coordinator at Washington State University Vancouver, for editing assistance. The authors are also appreciative of the anonymous peer reviewers for assistance.

The original article has been updated.

Publisher's Note Springer Nature remains neutral with regard to jurisdictional claims in published maps and institutional affiliations.

The original article can be found online at https://doi.org/10.1007/ s13187-021-02085-0.

Connie Kim Yen Nguyen-Truong

c.nguyen-truong@wsu.edu

1 College of Nursing, Washington State University, Vancouver, WA, USA

2 School of Nursing, University of Portland, Portland, OR, USA

3 Asian and Pacifc Islander Communities, Seattle, WA, USA

4 Asian and Pacifc Islander Communities, Portland, OR, USA

5 Micronesian Islander Community, Salem, OR, USA

6 Health Human Performance, and Athletics with an emphasis in Public Health, Linfeld University, Salem, OR, USA 